\title{
BẤT THƯờnG TĨNH MẠCH PHỔI BÁN PHẦN BÊN TRÁI ĐỔ VỀ TĨNH MẠCH VÔ DANH: NHÂN MộT TRƯờnG HợP LÂM SÀNG VÀ NHÌN LẠI Y VĂN
}

Dương Đức Hùng*, Phạm Quốc Đạt*, Phạm Thu Thủy*, Nguyễn Anh Huy**

\section{TÓM TÁ̀T}

Chúng tôi báo cáo nhân một trường hợp bất thường tĩnh mạch phổi bán phần bên trái đổ về tĩnh mạch vô danh được chần đoán và phẫu thuật tại đơn vị phẫu thuật tim mạch, bệnh viện Bạch Mai. Qua trường hợp này chùng tôi bàn luận về phương pháp chẩn đoán, điều trị và nhìn lại y văn về thể bất thường tĩnh mạch phổi này.

\section{I. ĐẬT VẤN ĐỂ}

Tĩnh mạch phổi trở về bất thường (anomaly of pulmonary venous connection) là một dị tật tim bẩm sinh, trong đó tối thiểu một trong các tĩnh mạch phổi không kết nối trực tiếp vào nhĩ trái, mà lại đổ về một tĩnh mạch hệ thống hoặc về nhĩ phải [1]. Trong đó, bất thường đổ về tĩnh mạch phổi bán phần khác với thể toàn phần là không phải toàn bộ các tĩnh mạch phổi mà chỉ một phần các tĩnh mạch phổi đổ về tĩnh mạch hệ thống hay nhĩ phải. Tĩnh mạch phổi trở về bất thường bên phải thường gặp hơn bên trái, liên quan đến thông liên nhĩ thể xoang tĩnh mạch, tĩnh mạch phổi trên phải đổ vào nhĩ phải hoặc tĩnh mạch chủ trên. Tuy nhiên cũng gặp trường hợp tĩnh mạch phổi phải đổ vào tĩnh mạch chủ dưới. Tĩnh mạch phổi trở về bất thường bên trái hiếm gặp hơn, thường là đổ vào tĩnh mạch vô danh, xoang tĩnh mạch vành, hiếm gặp hơn là đổ vào tĩnh mạch chủ, nhĩ phải, tĩnh mạch dưới đòn trái.

Chẩn đoán bệnh dựa vào lâm sàng, siêu âm tim, thông tim, cộng hưởng từ tim, cắt lớp vi tính dựng hình mạch phổi. Trong một số trường hợp, các triệu chứng lâm sàng không rõ ràng, thể bệnh ít gặp thì việc thăm khám kỹ và sử dụng các phương tiện cận lâm sàng là rất cần thiết.

Giải pháp điều trị phẫu thuật chủ yếu đối với tĩnh mạch phổi trở về bất thường hiện nay là phẫu thuật sửa chữa toàn bộ, chuyển các tĩnh mạch phổi trở về nhĩ trái và đóng lỗ thông liên nhĩ nếu có. Hai nguyên nhân chính thường gây tử vong sau mổ là tăng áp lực động mạch phổi và phù phổi cấp. Biến chứng nặng nhất sau mổ là hẹp miệng nối tĩnh mạch phổi (5 - 10\%) [1].

Chúng tôi đưa ra một trường hợp lâm sàng với thể bệnh của tĩnh mạch phổi trở về bất thường bán phần bên trái đổ về tĩnh mạch vô danh đã được khám, chẩn đoán và điều trị tại đơn vị phẫu thuật tim mạch, viện tim mạch Việt Nam, bệnh viện Bạch Mai để bàn luận về chẩn đoán, điều trị của bệnh nhân, và nhìn lại $\mathrm{y}$ văn về thể bất thường tĩnh mạch phổi này.

\section{CA LÂM SÀNG}

Bệnh nhân nữ, 33 tuổi, tiền sử khỏe mạnh. Vào viện vì tức ngực, khó thở. Bệnh diễn biến khoảng 1 tháng, bệnh nhân xuất hiện khó thở khi gắng sức, trống ngực. Khám: khó thở NYHA II, tim đều 100 lần/phút, phổi thông khí đều, không rales, gan to $1 \mathrm{~cm}$ dưới bờ sườn, tĩnh mạch cổ nối, thổi tâm thu 3/6 ổ van ba lá. Siêu âm tim lần 1: Thông liên nhĩ lỗ thứ hai, dạng sàng, trên phần phình vách liên nhĩ $25 \times 20 \mathrm{~mm}$ có nhiều lỗ thông liên nhĩ. Đường kính lỗ thông lớn nhất khoảng $17 \mathrm{x}$ $20 \mathrm{~mm}$, shunt trái - phải. Gờ van nhĩ - thất: $9 \mathrm{~mm}$, gờ động mạch: $1 \mathrm{~mm}$, gờ tĩnh mạch phổi phải: $10 \mathrm{~mm}$, gờ tĩnh mạch chủ trên: $13 \mathrm{~mm}$, gờ tĩnh mạch chủ dưới: $7 \mathrm{~mm}$. Giãn thất phải $(40 \mathrm{~mm})$, hở van ba lá nặng, tăng áp lực động mạch phổi nặng (PAPs $85 \mathrm{mmHg}$ ), không kèm theo dị tật bẩm sinh khác. Do có sự bất tương xứng giữa kích thước lỗ thông và mức độ tăng áp lực động mạch phổi, bệnh

\footnotetext{
* Bệnh viện Bạch Mai

** Truò̀ng đại học Y Hà Nội
}

Ngườ chịu trách nhiệm khoa học: TS Durong Đức Hùng

Ngày nhận bài: 01/11/2019 - Ngày Cho Phép Đăng: 20/12/2019

Phản Biện Khoa học: PGS.TS. Đặng Ngọc Hùng GS.TS. Lê Ngoc Thành 
nhân được làm siêu âm tim lần 2: thông liên nhĩ kiểu lỗ thứ hai dạng sàng $27 \times 22 \mathrm{~mm}$, shunt trái phải. Hình ảnh tĩnh mạch phổi đổ lạc chỗ bán phần thể trên tim, tĩnh mạch phổi trên trái đổ vào tĩnh mạch vô danh qua tĩnh mạch thẳng, tăng áp lực động mạch phổi nặng (PAPs 90mmHg). Bệnh nhân đã được chụp cắt lớp vi tính dựng hình hệ mạch phổi để khẳng định chẩn đoán. Kết quả: Hình ảnh thông liên nhĩ, giãn thất phải, giãn động mạch phổi, tĩnh mạch phổi thùy trên phổi trái đổ lạc chỗ vào tĩnh mạch vô danh (hình1). Thông tim: Qp/Qs: 3,1; Rp/Rs: 0,18.

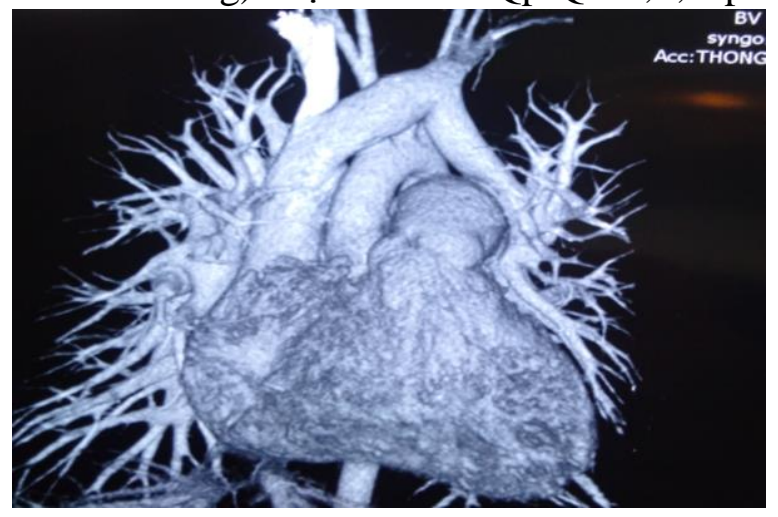

Hình 1: Bất thuờng tĩnh mạch phổi trên trái đổ về tĩnh mạch vô danh

Bệnh nhân được chỉ định phẫu thuật với chẩn đoán: Thông liên nhĩ lỗ thứ phát, tĩnh mạch phổi bất thường bên trái đổ về tĩnh mạch vô danh, hở van ba lá nặng, tăng áp lực động mạch phổi nặng.

Bệnh nhân được mở ngực theo đường dọc giữa xương ức, chạy máy tuần hoàn ngoài cơ thể ở nhiệt độ thường giữa động mạch chủ lên, và tĩnh mạch chủ trên và tĩnh mạch chủ dưới, liệt tim qua gốc động mạch chủ sử dụng dung dịch liệt tim máu ấm. Tổn thương: Tim phải giãn lớn, động mạch phổi lớn gấp đôi động mạch chủ, thông liên nhĩ lỗ thứ 2 dạng sàng, kích thước 20x22mm, hở van ba lá do giãn vòng van. Tĩnh mạch vô danh giãn, tĩnh mạch phổi trên trái đổ về tĩnh mạch vô danh qua tĩnh mạch thẳng. Tiến hành: Vá thông liên nhĩ, sửa van ba lá, cắt tĩnh mạch phổi trên trái tại vị trí tĩnh mạch vô danh, nối tĩnh mạch thẳng với tiểu nhĩ trái. Ngừng máy tim phổi nhân tạo, rút các ống, trung hòa heparin và đóng ngực theo giải phẫu. Tổng thời gian chạy tuần hoàn ngoài cơ thể 52 phút, thời gian kẹp chủ 29 phút. Tổng thời gian phẫu thuật 97 phút.

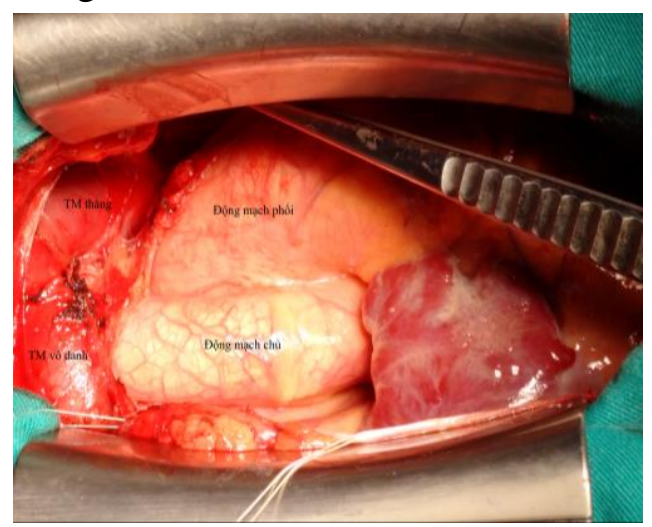

Hình 2. Tĩnh mạch phổi trên trái đổ về tĩnh mạch vô danh qua tĩnh mach thẳng

Sau mổ bệnh nhân được thở máy, hồi sức trạng toàn thân và huyết động ổn định. Bệnh nhân tích cực và rút ống nội khí quản sau $18 \mathrm{~h}$ trong tình ược tiếp tục điều trị nội khoa và ra viện sau mổ 7 
ngày. Siêu âm tim sau mổ cho kết quả tốt: 1ỗ thông liên nhĩ được đóng kín, hở ba lá nhẹ, không có hẹp lỗ đổ về của tĩnh mạch phổi trên trái.

\section{BÀN LUẬN}

Bất thường đổ về tĩnh mạch phổi gồm thể toàn bộ và bán phần. Trong đó, bất thường đổ về tĩnh mạch phổi bán phần là thể thường gặp hơn (80$90 \%$ các trường hợp) [2]. Đối với nhóm bất thường đổ về tĩnh mạch phổi bán phần, thông thường các tĩnh mạch phổi trái sẽ đổ bất thường vào tĩnh mạch chủ trên trái (tĩnh mạch vô danh) hoặc xoang vành, tĩnh mạch phổi phải sẽ đổ vào tĩnh mạch chủ trên phải, tĩnh mạch chủ dưới hoặc nhĩ phải. Tần suất bất thường của tĩnh mạch phổi phải gấp đôi tĩnh mạch phổi trái. Rất hiếm có sự đổ về bất thường chéo: tĩnh mạch phổi trái đổ vào tĩnh mạch chủ trên phải hay nhĩ phải. Bất thường đổ về tĩnh mạch phổi bán phần bao gồm các thể sau [3]:

- Tĩnh mạch phổi phải đổ vào tĩnh mạch chủ trên phải: thường chỉ một tĩnh mạch phổi trên phải, đôi khi cả 2 tĩnh mạch phổi phải đổ vào tĩnh mạch chủ trên ngay phía trên chỗ nối tĩnh mạch chủ trên với nhĩ phải. $80 \%$ trường hợp có phối hợp với thông liên nhĩ thể xoang tĩnh mạch.

- Tĩnh mạch phổi phải đổ vào tĩnh mạch chủ dưới: xảy ra ở cả 2 tĩnh mạch phổi phải trong $60 \%$ trường hợp, chỉ một tĩnh mạch phổi phải trong 40\% trường hợp. Chỉ có $20 \%$ trường hợp có phối hợp với thông liên nhĩ. Bất thường này nằm trong hội chứng Scimitar Syndrome.

- Tĩnh mạch phổi phải đổ vào nhĩ phải: thường kết hợp với thông liên nhĩ.

- Tĩnh mạch phổi trên trái đổ vào tĩnh mạch chủ trên trái hay tĩnh mạch vô danh: thường gặp nhất trong bất thường nối liền của tĩnh mạch phổi bên trái.

- Các bất thường hiếm hơn: tĩnh mạch phổi phải đổ vào xoang vành hay tĩnh mạch đơn. Cả hai tĩnh mạch phổi nên trái đổ và tĩnh mạch chủ trên trái. Một tĩnh mạch phổi trái đổ vào xoang vành [3].

Về biểu hiện lâm sàng, bất thường tĩnh mạch phổi bán phần có biểu hiện chủ yếu của tổn thương thông liên nhĩ: Biểu hiện của tăng tải thể tích nhĩ phải và thất phải [3]. Trên lâm sàng trong trường hợp của chúng tôi, bệnh nhân có biểu hiện khá điển hình. Tuy nhiên, việc phát hiện chính xác tổn thương bất thường tĩnh mạch phổi không phải dễ dàng, do có sự khác nhau về siêu âm tim giữa hai lần, chúng tôi đã đề nghị làm thêm cận lâm sàng chụp cắt lớp vi tính hệ mạch phổi để chẩn đoán xác định tổn thương. Như vậy, việc phát hiện tổn thương đòi hỏi bác sĩ lâm sàng phải khám xét rất tỉ mỉ, trong trường hợp này, sự bất tương xứng giữa lâm sàng, siêu âm tim, với kết quả thông liên nhĩ lỗ nhỏ nhưng tăng áp lực động mạch phổi rất nặng, đã giúp bác sĩ lâm sàng tìm kiếm những nguyên nhân khác giải thích được mức độ tăng áp lực động mạch phổi nặng đó.

Trên siêu tim, tĩnh mạch phổi ở vị trí bình thường có thể thấy được bằng các mặt cắt: 4 buồng từ mỏm, 5 buồng dưới sườn, mặt cắt trên hõm ức. Tĩnh mạch chủ trên trái (hay tĩnh mạch thẳng): có thể phát hiện được bắt mặt cắt trên hõm ức và mặt cắt dưới sườn. Khi xoang vành giãn rộng do thông thương với tĩnh mạch chủ trên trái, từ mặt cắt cạnh ức theo trục dọc (thấy rõ xoang vành) hơi nghiêng đầu dò có thể thấy rõ lộ trình của tĩnh mạch chủ trên trái. Tĩnh mạch vô danh: thấy được bằng mặt cắt trên hõm ức [3]. Với trường hợp tĩnh mạch phổi bất thường bên trái đổ về tĩnh mạch vô danh qua tĩnh mạch thẳng có thể thấy hình ảnh gián tiếp tĩnh mạch vô danh giãn, tĩnh mạch chủ trên giãn, hay hình ảnh trực tiếp của tĩnh mạch thẳng với dòng chảy ngược chiều đi vào tĩnh mạch vô danh (hình 3). 

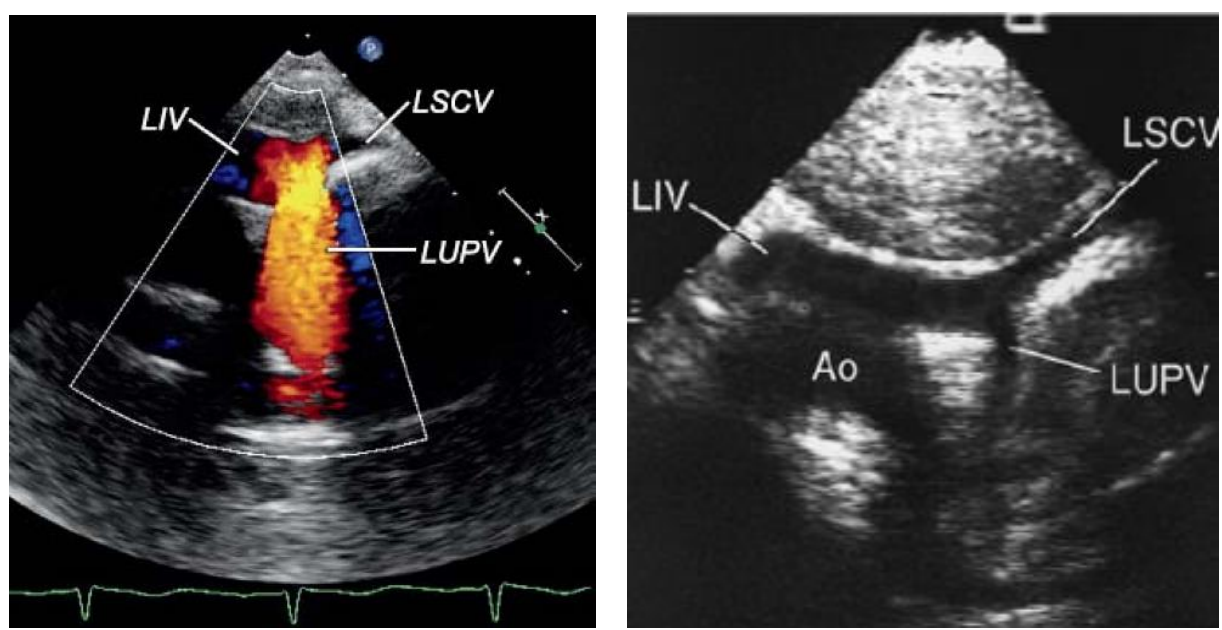

Hìn 3. Tĩnh mạch phổi trên trái (LUPV) đổ vào tĩnh mạch vô danh (LIV) ngay duoơi tĩnh mach chủ trên trái (LSVC)

Ngoài siêu âm tim, thì X-quang ngực, điện tâm đồ, cắt lớp vi tính hoặc cộng hưởng từ tim, thông tim cũng có vai trò trong chẩn đoán. Thông tim giúp khảo sát độ bão hòa oxy trong máu nhĩ phải, nhĩ trái, thất trái và các đại động mạch. Theo Brotmacher và Flemingnawm 1957, khi giá trị độ bão hòa oxy trong máu ở tĩnh mạch chủ trên trên vượt quá $88 \%$ thì chẩn đoán có nối liền bất thường tĩnh mạch phổi đổ vào tĩnh mạch chủ trên [4]. Theo tác giả Atsushi Nakahira, thực hiện thông tim cho tất cả các bệnh nhân trước mổ, ngoài các thông số như độ bão hòa oxy, tỷ lệ Qp: Qs, sức cản phổi...tác giả còn xác định vị trí tĩnh mạch phổi bất thường đổ vào tĩnh mạch chủ trên. Mục đích của tác giả là dựa vào thông tin này để định hướng phương pháp phẫu thuật [5].

Chỉ định phẫu thuật ở tất cả các bệnh nhân hồi lưu bất thường tĩnh mạch phổi bán phần có hoặc không có kèm thông liên nhĩ, nhất là khi tỉ lệ Qp:Qs $\geq 2$. Khi có dấu hiệu quá tải thể tích thất phải [4],[6],[7]. Chống chỉ định phẫu thuật khi bệnh nhân có hội chứng Eisenmenger (tăng áp lực động mạch phổi cố định).

Việc phẫu thuật bệnh lý này dựa trên nguyên tắc: đóng lỗ thông liên nhĩ nếu có và chuyển tĩnh mạch phổi bất thường về nhĩ trái. Bệnh nhân của chúng tôi được chọn giải pháp đóng thông liên nhĩ và nối tĩnh mạch thẳng với tiểu nhĩ trái đưa tĩnh mạch phổi đổ về nhĩ trái qua tiểu nhĩ trái (hình 4).
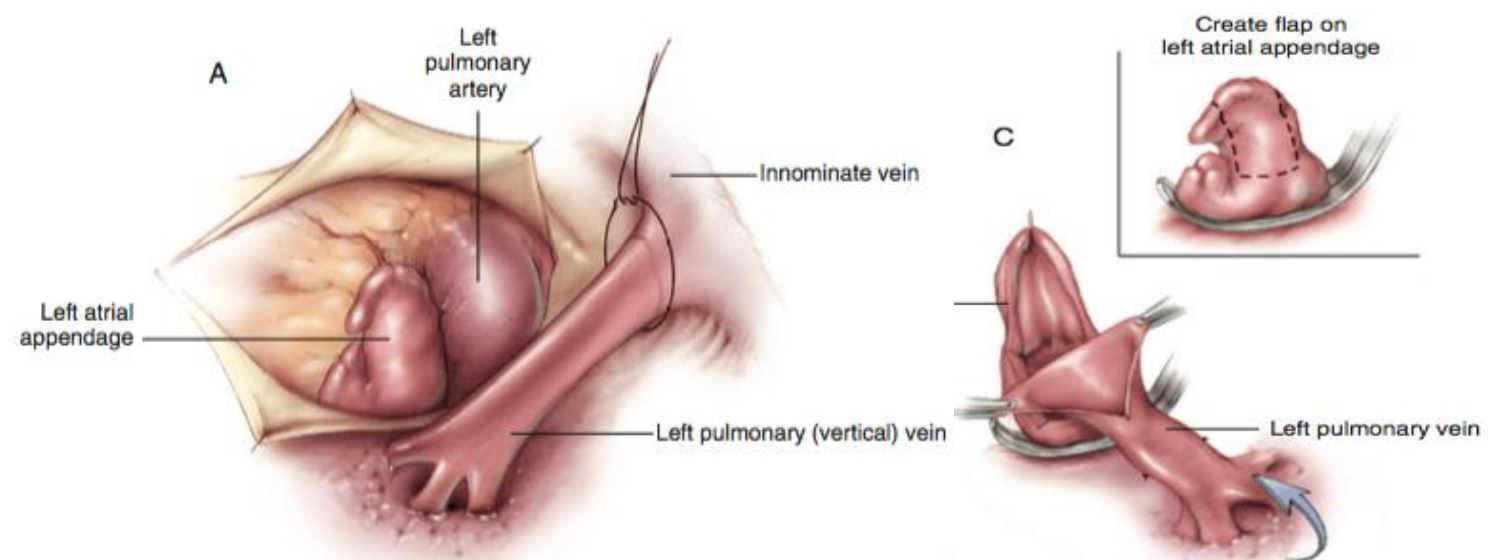

Hình 4. Cắt tĩnh mạch thẳng (vertical vein) sát tĩnh mạch vô danh (innomiate vein), nối với tiểu nhĩ trái (left atrial appendage) 
Theo dõi biến chứng sau phẫu thuật, ngoài các biến chứng chung của phẫu thuật và phẫu thuật tim như chảy máu sau mổ, suy hô hấp, suy tim, tăng áp lực động mạch phổi ... trong phẫu thuật sửa chữa bất thường tĩnh mạch phổi bán phần cần phải lưu ý về một số biến chứng sau đây:

- Hẹp tắc tĩnh mạch phổi là biến chứng thường gặp và nặng nhất. Nguyên nhân do kỹ thuật mổ, đường khâu bị hẹp, tĩnh mạch phổi bị gập. Vì vậy cần kiểm tra trong mổ, ngay sau mổ để phát hiện xử lý kịp thời.

- Hội chứng tĩnh mạch chủ trên xảy ra khi có hẹp tĩnh mạch chủ trên, khi sửa chữa bất thường tĩnh mạch phổi bên phải đổ về tĩnh mạch chủ trên, hoặc thắt tĩnh mạch thẳng lấn vào tĩnh mạch chủ trên trái gây hẹp. Bệnh nhân có thể có các triệu chứng của tình trạng tăng áp lực tĩnh mạch chủ trên, biểu hiện như: phù cổ mặt, sung huyết kết mạc, nuốt nghẹn [8].

- Rối loạn chức năng nút xoang: thường gặp với bất thường tĩnh mạch phổi bên phải đổ vào tĩnh mạch chủ trên.

Trong trường hợp của chúng tôi, bệnh nhân không gặp biến chứng nào sau phẫu thuật.

\section{KẾT LUẬN}

Bệnh lý bất thường đổ về tĩnh mạch phổi là một bệnh lý tim bẩm sinh hiếm gặp, chẩn đoán bệnh khó trong một số trường hợp. Tuy nhiên, nếu không chẩn đoán kịp thời và có phương pháp điều trị phù hợp có thể để lại những hậu quả nặng nề, tăng áp lực động mạch phổi cố định. Vì vậy cần kết hợp các phương pháp chẩn đoán để có thể chẩn đoán sớm cho bệnh nhân. Phẫu thuật với nguyên tắc vá thông liên nhĩ và chuyển lại bất thường tĩnh mạch phổi về nhĩ trái trong cùng một thì cho kết quả tốt.

\section{TÀI LIỆU THAM KHẢO}

1. Kirklin, Barratt - Boyes (2003), "Total anomalous pulmonary venous connection", Cardiac Surgery, $2^{\text {nd }}$ Edition, Churchil Livingston, NewYork, 753 -776.

2. Tiêu Chí Đức, Nguyễn Hoài Nam (2012), Các thay đổi bệnh lý trong hồi lưu tĩnh mạch phổi bất thường. Tạp chi Y hoc TP Hồ Chí Minh. 16 (1).

3. Phạm Nguyễn Vinh (2006). "Nối liền bất thường tĩnh mạch phổi”. Bệnh học Tim Mạch. Nhà xuất bản Y học, 3 , Thành phố Hồ Chí Minh, tập 2, tr 520-27

4. Gotsman MS., Astley R., and Parsons CG. (1965). "Partial Anomalous Pulmonary Venous Drainage in Association With Atrial Septal Defect". Brit Heart J , 27, pp 566- 77.

5. Nakahira A, Yagihara T, Kagisaki K, Hagino I, Ishizaka T, Koh M, Uemura H, and Kitamura S (2006). "Partial Anomalous Pulmonary Venous Connection to the Superior Vena Cava". Ann Thorac Surg, Elsevier Inc,82, pp 978-82.

6. Backer CL and Mavroudis C (2003). "Atrial Septal Defects. Partial Anomalous Pulmonary Venous Connection, And Scimitar Syndrome". Mavroudis-Pediatric Cardiac Surgery. Mosby Elsevier, 3rd, U.S.A , pp 283-97

7. Kouchoukos NT., Blackstone EH., Doty DB, Hanley FL., Karp RB. (2003). “Atrial Septal Defect And Partial Anomalous Pulmonary Venous Connection ". Kirklin/Barratt-BoyesCardiac Surgery. Churchill Livingstone, 3rd, USA.Vol 1,pp 715 - 52

8. Dương Đức Hùng (2001). "Hội chứng tĩnh mạch chủ trên và vai trò của phẫu thuật". Phẫu thuật cấp cứu tim mạch và lồng ngực, Nhà xuất bản Y học, Hà Nội. tr.208- 18. 